\title{
Dissolved Organic Matter Processing in Pristine Antarctic Streams
}

\author{
Morimaru Kida,* Nobuhide Fujitake,* Taichi Kojima, Yukiko Tanabe, Kentaro Hayashi, Sakae Kudoh, \\ and Thorsten Dittmar*
}

Cite This: Environ. Sci. Technol. 2021, 55, 10175-10185

Read Online

ACCESS | Lل|ll Metrics \& More | 回 Article Recommendations | st Supporting Information

ABSTRACT: Accelerated glacier melt and runoff may lead to inputs of labile dissolved organic matter (DOM) to downstream ecosystems and stimulate the associated biogeochemical processes. However, still little is known about glacial DOM composition and its downstream processing before entering the ocean, although the function of DOM in food webs and ecosystems largely depends on its composition. Here, we employ a set of molecular and optical techniques (UV-vis absorption and fluorescence spectroscopy, ${ }^{1} \mathrm{H} \mathrm{NMR}$, and ultrahigh-resolution mass spectrometry) to elucidate the composition of DOM in Antarctic glacial streams and its downstream change. Glacial DOM consisted largely of a mixture of small microbial-derived biomolecules. ${ }^{1} \mathrm{H}$ NMR analysis of bulk water revealed that these small molecules were

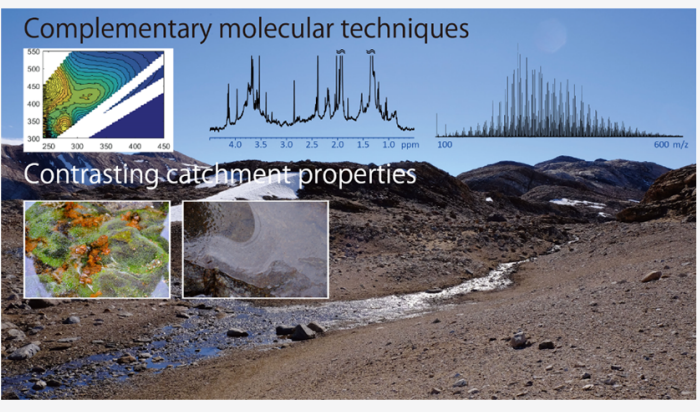
processed downstream into more complex, structurally unrecognizable molecules. The extent of processing varied between streams. By applying multivariate statistical (compositional data) analysis of the DOM molecular data, we identified molecular compounds that were tightly associated and moved in parallel in the glacial streams. Lakes in the middle of the flow paths enhanced water residence time and allowed for both more DOM processing and production. In conclusion, downstream processing of glacial DOM is substantial in Antarctica and affects the amounts of biologically labile substrates that enter the ocean.

KEYWORDS: DOM, microbial processing, glacial, stream, FT-ICR MS, NMR, EEM, PARAFAC

\section{INTRODUCTION}

Dissolved organic matter (DOM) is a highly heterogeneous mixture of numerous organic compounds that collectively play an essential role in key ecosystem processes. ${ }^{1,2}$ It ubiquitously exists in natural waters and contains a similar mass of carbon as atmospheric $\mathrm{CO}_{2}$ or the global biomass. ${ }^{3}$ As such, DOM is an important component of global biogeochemical cycles. Although the reactivity and functions of DOM have been linked to its composition, ${ }^{4,5}$ DOM remains poorly characterized at the molecular level because of its extreme heterogeneity and polydispersity. ${ }^{6,7}$ Studying DOM composition is fundamentally important because it largely controls photoreactivity, bioavailability, and ultimately persistence of DOM in the environment. ${ }^{4,8}$ Understanding environmental and anthropogenic impacts on DOM composition is also important for water quality, carbon cycling, and feedback to human society. ${ }^{9,10}$

Increasing air temperatures alters the Antarctic hydrologic cycle by melting glaciers and ice sheets, which contain approximately $70 \%$ of freshwater on Earth, increase water discharge to the oceans, and ultimately raise the global mean sea level. ${ }^{11}$ Satellite gravimetry has shown that mass loss of Antarctic glacial ice has significantly accelerated since 2006 . $^{12}$ Glacial ice contains a detectable amount of labile, small organic molecules, ${ }^{13,14}$ and such organic carbon is released from glaciers through melt at the glacier surface that discharges at the glacier terminus or by glacier calving, thereby contributing to downstream biogeochemical cycles. ${ }^{15}$ Consequently, glacial runoff has been suggested to be a quantitatively important source of labile DOM to marine ecosystems. ${ }^{15}$

Nevertheless, detailed studies of DOM in polar glacial environments are scarce. Given the importance of polar glacial environments in the global $\mathrm{C}$ cycle and as a sentinel of climate change, DOM composition in glacial meltwater and its downstream change are an important subject of research. In this study, we examined the DOM composition of streams from the Langhovde ice-free area on Sôya Coast (LützowHolm Bay, East Dronning Maud Land, East Antarctica) using complementary analytical techniques, namely, ${ }^{1} \mathrm{H}$ nuclear magnetic resonance spectroscopy (NMR), Fourier-transform ion cyclotron resonance mass spectrometry (FT-ICR MS), and excitation-emission matrix spectroscopy combined with parallel factor analysis (EEM-PARAFAC). The complementary nature of these methods enables the characterization of major DOM constituents and their processing under different environmental settings on a molecular level. ${ }^{6,14}$

Received: May 17, 2021

Revised: June 29, 2021

Accepted: June 29, 2021

Published: July 9, 2021

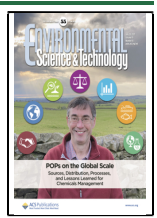


We hypothesized that (i) glacial DOM in Langhovde consists largely of a mixture of small biomolecules, and if this is the case, (ii) these small molecules are actively processed downstream before entering the ocean. We further investigated if the degree of downstream processing of DOM depends on environmental and hydrological conditions such as vegetation and the existence of lakes in the middle of the flow paths.

\section{MATERIALS AND METHODS}

2.1. Study Area. The sampling campaign was conducted during the austral summer in January 2017 as a part of the 58th Japanese Antarctic Research Expedition. There are several icefree areas on Soya Coast with hundreds of lakes and several streams, which were formed during the last 7000 years under the glacier retreat and isostatic uplifts that occurred after the Last Glacial Maximum. ${ }^{16}$ The Langhovde ice-free area is located $\sim 25 \mathrm{~km}$ away from Japan's Syowa Station. The Yukidori and Yatsude Valleys in Langhovde run from the edge of the continental ice sheet to Lutzow-Holm Bay (Figure S1). The streams are fed by meltwater from the glacier and flow on the impermeable bedrock, with coarse gravel and sandy deposits covering the bedrock. In the middle of the valleys are Lakes Yukidori ( $8.6 \mathrm{~m}$ depth) and Heito (4.5 m depth) (Figure S1). Lake Heito is formed behind a natural snow dam in the upper section of the Yatsude Valley. These streams are separated by a rocky hill and they share a common climate, geology, and glacier as the sole water supply, but differ in vegetation. Many of the neighboring valleys (including the Yukidori Valley) and lakes in the southern part of the Langhovde area contain well-developed colonies of mosses, algae, and lichens. ${ }^{17}$ In contrast, Lake Heito and the stream below the snow dam in the Yatsude Valley contain very little flora. Such a contrast in the distribution and colonization of flora may have resulted from the repeated physical disturbances induced by breaching of the dam once per decades. ${ }^{18}$ This contrasting vegetation allowed us to evaluate the possible influence of vegetation on DOM composition. Snow petrels (Pagodroma nivea) and south polar skuas (Stercorarius maccormicki) inhabit during the short summer period in both valleys, which is the main nutrient source for vegetation. These streams appear only during the short austral summer, when the valleys receive melt water inputs from the glacier and patchy snows, which limited the sampling of stream water to that period of a year. Stream samples were collected at approximately regular intervals from the beginning (glacial meltwater) to the end (before the outlet to the sea) of each stream (Figure S1). Information regarding sample handling is given in the Supporting Information.

2.2. Optical Analysis and Basic Bulk Parameters. UVvis absorption spectra and fluorescence EEMs were measured on site, immediately after sampling and filtration (GF-75, Advantec, Tokyo, Japan) as previously reported. ${ }^{19}$ Briefly, UV-vis absorption spectra were measured using a GENESYS 10S UV-visible spectrophotometer with a $5 \mathrm{~cm}$ path length quartz cuvette. Absorbance data in this paper are expressed as Napierian absorption coefficients $\left(a_{\lambda}, \mathrm{m}^{-1}\right) \cdot{ }^{20,21}$ Fluorescence EEMs were collected with a FluoroMax- 4 spectrofluorometer. The EEMs were corrected for all necessary steps to remove biases and normalized in Raman units (RU). ${ }^{22}$ The spectral slope $\left(S_{275-295} \text {, in } \mathrm{nm}^{-1}\right)^{20,23}$ and dissolved organic carbon (DOC)-specific ultraviolet absorbance $\left(\mathrm{SUVA}_{254}\right.$, in $\mathrm{L} \mathrm{mg} \mathrm{C} \mathrm{Cl}^{-1}$ $\left.\mathrm{m}^{-1}\right)^{5}$ were calculated as previously reported (Table $\mathrm{S} 1$ ). Overlapping fluorescence spectra in EEMs were deconvoluted by PARAFAC. ${ }^{24}$ For PARAFAC, we used EEM data collected from Sôya Coast lakes in addition to the stream samples. ${ }^{19}$ The identified seven components, which collectively explained $>99.95 \%$ of the variability of sample EEMs, were named according to their rounded fluorescence emission maximum: $\mathrm{C}_{325}, \mathrm{C}_{415}, \mathrm{C}_{360}, \mathrm{C}_{500}, \mathrm{C}_{440}, \mathrm{C}_{460}$, and $\mathrm{C}_{300}$, with variation explained by each component decreasing sequentially from $\mathrm{C}_{325}$ to $\mathrm{C}_{300}$ (Table S1). ${ }^{19}$

DOC and total dissolved nitrogen (TDN) were measured in the laboratory in Japan using a total organic carbon analyzer combined with a total nitrogen measuring unit (TOC- $\mathrm{L}_{\mathrm{CPH}}$, Shimadzu, Kyoto, Japan) as in ref 25. Dissolved inorganic nutrients $\left(\mathrm{PO}_{4}{ }^{3-}, \mathrm{NH}_{4}{ }^{+}, \mathrm{NO}_{2}{ }^{-}, \mathrm{NO}_{3}{ }^{-}\right.$, and $\left.\mathrm{SiO}_{3}{ }^{2-}\right)$ were determined colorimetrically using an autoanalyzer as previously reported. ${ }^{26}$ The detection and quantification limits (in $\mu \mathrm{M}$ ) for inorganic nutrients were 0.01 and 0.06 for $\mathrm{PO}_{4}{ }^{3-}, 0.01$ and 0.12 for $\mathrm{NH}_{4}{ }^{+}, 0.01$ and 0.07 for $\mathrm{NO}_{2}{ }^{-}$, and 0.03 and 0.47 for $\mathrm{NO}_{3}{ }^{-}$. Details about sample handling and storing were previously reported. ${ }^{19}$ Dissolved organic nitrogen (DON) concentrations were calculated as the difference between the TDN and DIN concentrations, and the proportion of DON in TDN (\%DON) was subsequently calculated.

2.3. Bulk Water ${ }^{1} \mathrm{H}$ NMR. We employed SPR-W5WATERGATE ${ }^{1} \mathrm{H}$ NMR spectroscopy for bulk $\mathrm{DOM}^{27}$ on a Bruker AVANCE 500 spectrometer (Bruker GmbH, Karlsruhe, Germany) (Table S1). This sequence achieves very high sensitivity for low-abundant DOC samples by effectively deleting the water ${ }^{1} \mathrm{H}$ signal, with a slight attenuation of signals up to $1.1 \mathrm{ppm}$ on either side of the water resonance. ${ }^{27}$ Experimental preparations and settings generally followed those previously described. ${ }^{28}$ In addition, to facilitate NMR analysis, samples corresponding to $0.05 \mathrm{mg} \mathrm{C}(4.2 \mu \mathrm{mol} \mathrm{C})$ were evapo-concentrated using a small pear-shaped flask and rotary evaporator at $<40{ }^{\circ} \mathrm{C}$ with care not to totally dry up. Concentrates were transferred to glass vials with repeated washing of $\mathrm{D}_{2} \mathrm{O}$, filtered with precleaned glass fiber syringe filters (Whatman GF/F) using a glass syringe with a Teflon plunger tip, and transferred to $5 \mathrm{~mm}$ Shigemi NMR tubes. The average recovery rate of $87 \%$ on a DOC basis was achieved. A slight loss was possibly due to any or combination of volatilization of small organic molecules, precipitation during rotary evaporation, and retention on the flask wall and glass fiber filters. We did not use $\mathrm{NaOD}$ because the addition of $\mathrm{NaOD}$ produced insoluble precipitates, most likely $\mathrm{Na}_{2} \mathrm{SO}_{4}$ due to its relatively low solubility. The measurement time could be shortened drastically ( $1-2 \mathrm{~h}$ per sample) thanks to evapo-concentration compared to natural abundance measurements $(\sim 30 \mathrm{~h}) .{ }^{13}$ Fourier transformation, phase correction, and integration were done using TopSpin 3.6.2 (Bruker $\mathrm{GmbH}$, Karlsruhe, Germany). Chemical shift assignments were based on previous reports: ${ }^{6,29}$ methyl, methylene, and purely aliphatic protons ( $\mathrm{HC} \geq 4$ bonds away from next heteroatom, $\delta_{\mathrm{H}} \sim 0.5-1.6 \mathrm{ppm}$ ); functionalized protons ( $\mathrm{HC} \geq 2$ bonds away from next heteroatom, $\left.\delta_{\mathrm{H}} \sim 1.6-3.1 \mathrm{ppm}\right)$ including those of carboxyl-rich alicyclic molecules (CRAM, $\delta_{\mathrm{H}} \geq \sim 2.2$ ppm); ${ }^{30}$ methoxy, alcohols, esters, and sugar/aminosugar protons (3.1-4.4 ppm); and aromatic protons (mainly from amino acid side chains) $(6.5-8.3 \mathrm{ppm})$. Signals from lactic (1.27-1.39 ppm) and acetic (1.86-1.98 ppm) acids with varying intensity and width were present in all samples (Figures 2 and S3). Too broad signals in these chemical shift regions in some samples were problematic in that it can give false impressions of the relative spectral intensity between the 
Table 1. General Water Chemistry in the Yukidori and Yatsude Streams

\begin{tabular}{|c|c|c|c|c|c|c|c|c|c|c|c|c|c|c|}
\hline $\begin{array}{l}\text { sample } \\
\text { name }^{b}\end{array}$ & $\begin{array}{c}\mathrm{EC}^{a} \\
\left(\mathrm{mS} \mathrm{m}^{-1}\right)\end{array}$ & $\mathrm{pH}$ & $\begin{array}{l}\text { temp. } \\
\left({ }^{\circ} \mathrm{C}\right)\end{array}$ & $\begin{array}{l}\mathrm{DOC}^{a} \\
(\mu \mathrm{M})\end{array}$ & $\begin{array}{c}{ }^{a} \\
\left(\mathrm{~m}^{-1}\right)\end{array}$ & $\begin{array}{l}\text { TDN } \\
(\mu \mathrm{M})\end{array}$ & $\begin{array}{c}\mathrm{DON}^{a} \\
(\mu \mathrm{M})\end{array}$ & $\% \underset{(\%)}{\mathrm{DON}}$ & $\begin{array}{l}\mathrm{DOC} / \mathrm{DON}^{a} \\
\text { (molar ratio) }\end{array}$ & $\begin{array}{l}\mathrm{NO}_{2}^{-} \\
(\mu \mathrm{M})\end{array}$ & $\begin{array}{l}\mathrm{NO}_{3}^{-} \\
(\mu \mathrm{M})\end{array}$ & $\begin{array}{l}\mathrm{NH}_{4} \\
(\mu \mathrm{M})^{+}\end{array}$ & $\begin{array}{c}\mathrm{PO}_{4}^{3-} \\
(\mu \mathrm{M})\end{array}$ & $\begin{array}{c}\mathrm{SiO}_{3}^{2-} \\
(\mu \mathrm{M})\end{array}$ \\
\hline Yukidori $^{1}$ & 3.0 & 8.6 & 1.2 & 27.1 & 0.79 & 18.1 & 5.1 & 28.2 & 5.3 & 0.57 & 12.18 & 0.22 & ND & 6.16 \\
\hline Yukidori $^{2}$ & 7.5 & 10.0 & 1.5 & 60.3 & 1.65 & 66.5 & 6.9 & 10.4 & 8.8 & 1.54 & 57.82 & 0.21 & $\operatorname{Tr}$ & 26.52 \\
\hline Yukidori $^{3}$ & 6.8 & 8.6 & 2.5 & 55.3 & 1.40 & 66.3 & 7.6 & 11.4 & 7.3 & 1.00 & 57.53 & 0.18 & ND & 19.62 \\
\hline Yukidori $^{4}$ & 7.6 & 8.1 & 3.6 & 46.1 & 1.21 & 64.3 & 5.6 & 8.7 & 8.3 & 0.59 & 57.94 & 0.19 & $\operatorname{Tr}$ & 17.50 \\
\hline L. Yukidori & 6.0 & 8.2 & 6.6 & 74.5 & 0.71 & 10.6 & 8.0 & 75.6 & 9.3 & ND & 2.33 & 0.27 & $\operatorname{Tr}$ & 16.17 \\
\hline Yukidori ${ }^{6}$ & 6.7 & 7.1 & 8.3 & 70.8 & 0.82 & 11.9 & 8.7 & 72.9 & 8.2 & $\operatorname{Tr}$ & 3.06 & 0.15 & $\operatorname{Tr}$ & 23.70 \\
\hline Yukidori $^{7}$ & 8.1 & 7.1 & 4.8 & 40.1 & 0.91 & 29.9 & 8.4 & 28.2 & 4.8 & ND & 21.29 & 0.16 & $\operatorname{Tr}$ & 27.29 \\
\hline Yukidori $^{8}$ & 9.3 & 7.1 & 7.9 & 43.7 & 1.29 & 36.6 & 10.0 & 27.4 & 4.4 & $\operatorname{Tr}$ & 26.31 & 0.16 & ND & 42.12 \\
\hline Yukidori ${ }^{9}$ & 9.2 & 6.8 & 8.0 & 56.4 & 1.75 & 34.4 & 10.6 & 30.7 & 5.3 & 0.15 & 23.36 & 0.31 & ND & 34.38 \\
\hline Yatsude $^{1}$ & 10.1 & 7.2 & 1.8 & 36.4 & 0.89 & 10.5 & 4.3 & 40.8 & 8.5 & 0.13 & 5.96 & 0.14 & ND & 50.30 \\
\hline L. Heito & 3.6 & 7.3 & 1.8 & 53.7 & 1.19 & 15.8 & 12.0 & 76.3 & 4.5 & 0.20 & 3.38 & 0.17 & ND & 4.50 \\
\hline Yatsude $^{3}$ & 7.3 & 7.1 & 1.0 & 34.4 & 0.81 & 8.0 & 6.4 & 79.9 & 5.4 & 0.21 & 1.38 & ND & ND & 15.99 \\
\hline Yatsude $^{4}$ & 9.0 & 7.2 & 0.9 & 38.3 & 1.07 & 22.1 & 5.1 & 22.9 & 7.6 & 0.25 & 16.62 & 0.18 & $\operatorname{Tr}$ & 17.79 \\
\hline Yatsude $^{5}$ & 9.5 & 7.2 & 1.1 & 47.0 & 0.90 & 27.1 & 7.6 & 28.2 & 6.2 & 0.08 & 19.05 & 0.31 & $\operatorname{Tr}$ & 19.11 \\
\hline Yatsude $^{6}$ & 8.7 & 7.0 & 2.2 & 59.0 & 1.26 & 56.6 & 12.2 & 21.5 & 4.8 & $\operatorname{Tr}$ & 44.26 & 0.14 & 0.07 & 19.37 \\
\hline Yatsude $^{7}$ & 9.1 & 6.9 & 2.1 & 57.5 & 1.30 & 63.9 & 9.7 & 15.2 & 5.9 & 0.17 & 53.85 & 0.13 & $\operatorname{Tr}$ & 18.85 \\
\hline Yatsude $^{8}$ & 7.0 & 7.1 & 5.0 & 26.6 & 0.70 & 49.6 & 9.2 & 18.5 & 2.9 & 0.08 & 40.22 & $\operatorname{Tr}$ & $\operatorname{Tr}$ & 11.95 \\
\hline Yatsude $^{9}$ & 11.3 & 7.1 & 3.0 & 53.5 & 0.69 & 52.1 & 11.1 & 21.3 & 4.8 & $\operatorname{Tr}$ & 40.82 & $\operatorname{Tr}$ & ND & 40.76 \\
\hline
\end{tabular}

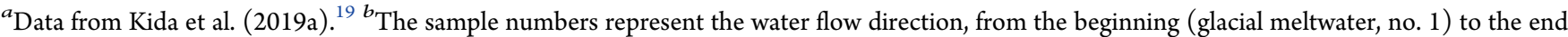
(no. 9) of each stream. Abbreviations: Tr, below the quantification limit; ND, below the detection limit; EC, electrical conductivity; $a_{254}$, absorption coefficient of DOM at $254 \mathrm{~nm}$; TDN, total dissolved nitrogen; DON, dissolved organic nitrogen; and \%DON, nitrogen-based percent of DON in TDN.

preassigned chemical shift regions. We excluded the corresponding regions from the integration, following past literature. $^{31}$

2.4. DOM Extraction and FT-ICR MS. DOM was extracted and desalted prior to FT-ICR MS analysis following an established method ${ }^{32}$ using cartridges filled with a styrene divinylbenzene copolymer (Agilent Bond Elut PPL, $100 \mathrm{mg}$ ). Depending on the DOC concentration, the volume used for extraction was adjusted, such that $4 \mu \mathrm{mol} \mathrm{C}$ was applied to each cartridge. The extraction of DOM inevitably leads to some fractionation of DOM molecules, ${ }^{28,33,34}$ but it was necessary for high-quality FT-ICR MS analysis. In this study, the extraction efficiency was $14-33 \%$ on a DOC basis (Table S2). We performed mass spectrometric analysis of DOM extracts via FT-ICR MS on a $15 \mathrm{~T}$ solariX XR Fouriertransform ion cyclotron resonance mass spectrometer (Bruker Daltonik GmbH, Bremen, Germany). The system was equipped with an electrospray ionization source (ESI, Bruker Apollo II) applied in negative ionization mode. Methanol extracts were mixed with ultrapure water $(50: 50 \mathrm{v} / \mathrm{v})$ for FTICR MS analysis and diluted to a final DOC concentration of $2.5 \mathrm{mg} \mathrm{C} \mathrm{L}{ }^{-1}$. 200 single scans with an ion accumulation time of $0.1 \mathrm{~s}$ were recorded over a mass range of $\mathrm{m} / z$ 92-2000 Da and added to one spectrum. Data processing, molecular formula assignments, and compound category classifications were done with the software package ICBM-OCEAN; ${ }^{35}$ details are explained in the Supporting Information (Section 2).

2.5. Calculation of DOM Functional Molecular Diversity. The functional molecular diversity of DOM analyzed by FT-ICR MS was calculated according to Mentges et $\mathrm{al}^{36}$ In the chemical context, the functional diversity is computed as a distance function using the absolute difference between any two molecular formulae with respect to a given chemical property. The value of the functional diversity can be interpreted as the expected difference between two molecules with respect to the selected property. ${ }^{36}$ In this study, the functional diversity was calculated with $\mathrm{m} / z$ and number of $\mathrm{C}$ atoms as indicators of molecular weight, hydrogen-to-carbon $(\mathrm{H} / \mathrm{C})$ ratio as an indicator of saturation, nitrogen-to-carbon $(\mathrm{N} / \mathrm{C})$ ratio as an indicator of relative nitrogen richness, and the modified aromaticity index $\left(\mathrm{AI}_{\text {mod }}\right)^{37}$ and double-bond equivalent (DBE) as indicators of DOM aromaticity.

2.6. Statistics/CoDa Analysis. We introduce the concept of compositional data ( $\mathrm{CoDa}$ ) analysis ${ }^{38}$ to multivariate analysis of DOM molecular group data obtained by the set of analytical techniques to account for their compositional nature. $\mathrm{CoDa}$ are vectors with strictly positive components (e.g., percentages, concentrations, frequencies, abundances, and shares) describing parts of a whole. Ratios between components are considered to be relevant to decipher the information of interest (for a latest good overview on CoDa analysis, see ref 38 ). It is increasingly recognized that special care needs to be paid in relation to sample data geometry when working with $\mathrm{CoDa}$. In $\mathrm{CoDa}$, the sample space is constrained, endowed with a Euclidean-type geometry (called Aitchison geometry), which is different from the usual one. ${ }^{38}$ Often, DOM compositions are represented in percentages of groups, such as the relative abundances of PARAFAC components, of proton distributions, and of molecular formulae. These percentage data are an obvious example of CoDa. Directly applying statistical techniques that were developed for original data in the ordinary Euclidean geometry (such as correlation analysis and principal component analysis) on these "closed" or "raw" compositional data is often statistically inadequate and may lead to misleading, spurious results. ${ }^{39,40}$ Generally speaking, most classical statistical method based on a linear relationship between variables may be unable to properly handle CoDa, which was already recognized by Pearson ${ }^{41}$ but unfortunately largely ignored in the literature, ${ }^{42,43}$ also in DOM research.

We therefore conducted a CoDa version of principal component analysis (CoDa-PCA) on DOM molecular group data. The original group data in a $\mathrm{D}$-dimensional constrained space was centered logratio (clr)-transformed by 


\section{Yukidori Valley}

\section{Yatsude Valley}
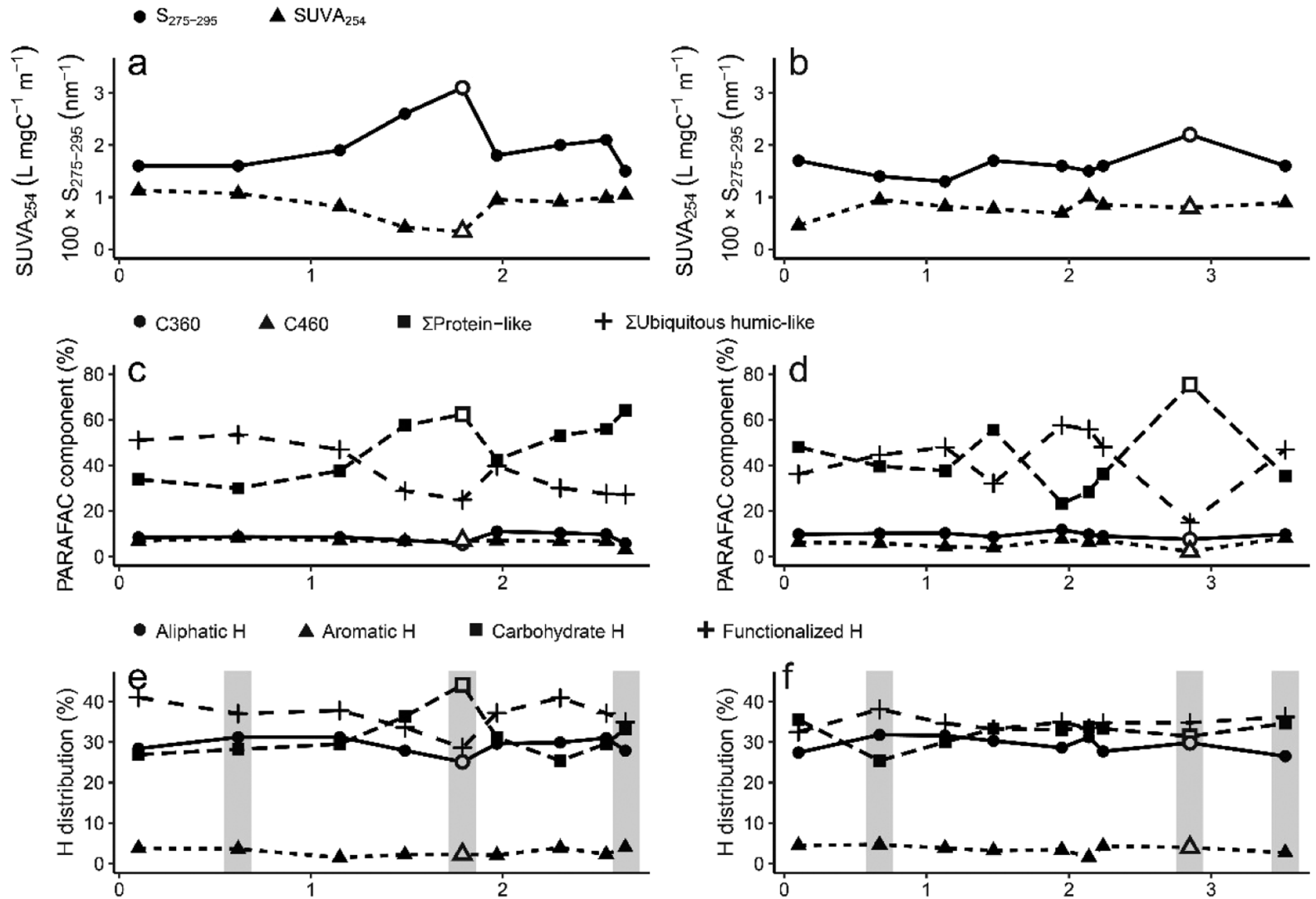

+ Functionalized $\mathrm{H}$
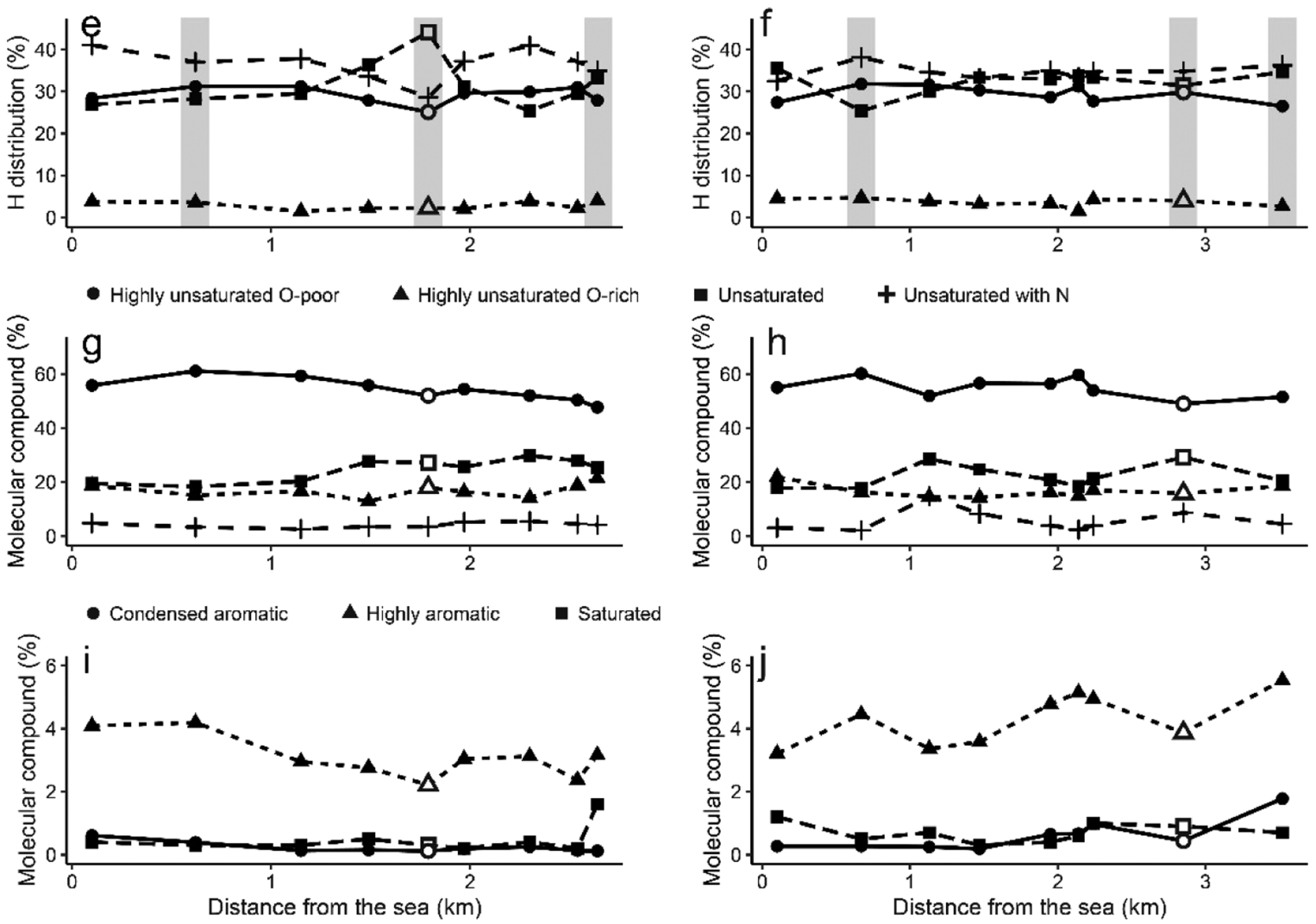

Figure 1. DOM composition downstream changes (right to left) in the Yukidori (left column) and Yatsude Valleys (right column). (a,b) Chromophoric DOM properties; (c,d) fluorescent DOM composition resolved by parallel factor analysis; $(\mathrm{e}, \mathrm{f}){ }^{1} \mathrm{H}$ distribution by bulk DOM ${ }^{1} \mathrm{H}$ NMR spectroscopy; (g,h) major molecular compound groups estimated by FT-ICR MS; and (i,j) minor molecular compound groups. Blank symbols represent lake water samples. ${ }^{1} \mathrm{H}$ NMR spectra of the samples highlighted by shading (e,f) are presented in Figure 2. Abbreviations: SUVA $_{254}$, specific UV absorbance at $254 \mathrm{~nm} ; S_{275-295}$, spectral slope determined between 275 and $295 \mathrm{~nm}$; Lubiquitous humic-like, sum of percent ubiquitous humic-like fluorescence components; $\Sigma$ protein-like, sum of percent protein-like fluorescence components; and functionalized $\mathrm{H}$, functionalized aliphatic protons with heteroatoms 2 or more bonds away, including CRAM. ${ }^{30}$ (a-d) Data from Kida et al. (2019a). ${ }^{19}$

$$
\operatorname{clr}(\mathbf{x})=\left(\ln \frac{x_{i}}{g(\mathbf{x})}\right)_{i=1, \ldots, D} \quad \text { with } g(\mathbf{x})=\sqrt[n]{x_{1} \cdot x_{2} \ldots x_{D}}
$$

using the robComposition package. ${ }^{44}$ Here, the four compositions were taken as a single composition to compute the clr. Subsequently, PCA was performed on clr-transformed data using the R prcomp function ${ }^{45}$ with centering. ${ }^{38,40}$ Because one 


\section{a) Yukidori Valley}

Yukidori 8
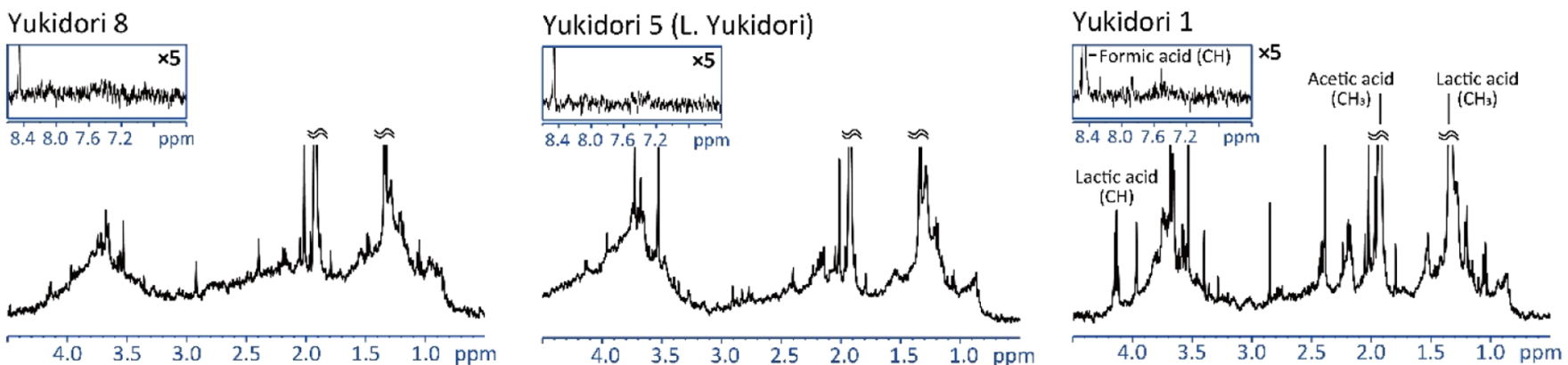

b) Yatsude Valley
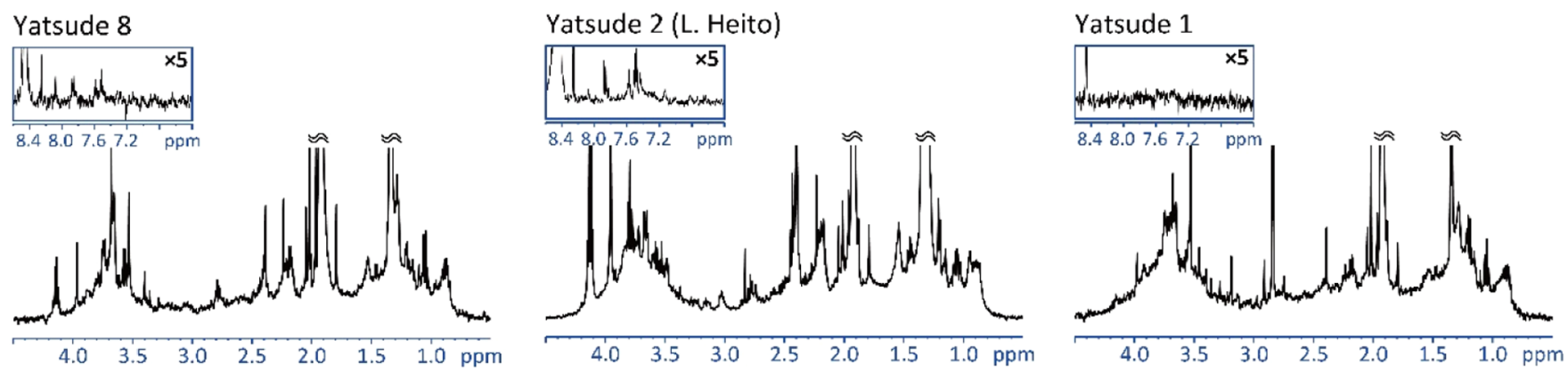

Figure 2. Magnified ${ }^{1} \mathrm{H}$ NMR spectra of the samples highlighted by shading in Figure le,f. Insets for ${ }^{1} \mathrm{H}$ NMR spectra are the aromatic ${ }^{1} \mathrm{H}$ region that is magnified by a factor of 5 relative to the original magnified spectra. Signals by $\mathrm{CH}_{3}$ of lactic and acetic acids and by $\mathrm{CH}$ of formic acid (inset) are cropped.

sample had a zero value of a fluorescence component $\mathrm{C}_{300}$, we removed $\mathrm{C}_{300}$ from the analysis. In the case of CoDa-PCA, the interpretation of a single variable and the correlations between (original) variables cannot be assessed as in ordinary PCA because all clr-transformed variables are essentially dependent on one another through the geometric mean of the composition. Only two most frequently used properties for the interpretation of compositional variability are introduced here. First, the lengths of the arrows in the covariance biplot are, up to the projection, approximations of the standard deviation of the corresponding clr-transformed variable, $\operatorname{clr}\left(x_{i}\right)$ $=\ln \left(x_{i} / g(\mathbf{x})\right)$. Second, the distances between the vertices of the $i$-th and the $k$-th clr-variable are approximations, up to the projection, of the standard deviation of the corresponding log ratio, $\ln \left(x_{i} / x_{k}\right)$. The second point means that if the vertices of the two arrows nearly coincide, it indicates that the variance $\ln \left(x_{i} / x_{k}\right)$ is nearly zero, so that the ratio $x_{i} / x_{k}$ is nearly constant. For other interpretations of CoDa-PCA biplots, we refer to the literature. ${ }^{38,46} \mathrm{We}$ also computed the variation array $^{47}$ and analytical precision of FT-ICR MS to confirm the findings of CoDa-PCA (Tables S3 and S4), as the graphical representation depends on the projection. The larger the variability captured in the biplot, the more confident one can be in the visual findings.

\section{RESULTS}

The Yukidori and Yatsude stream samples had high DIN concentrations and low \%DON (Table 1). Nitrate was by far dominant among DIN and it showed clear spatial trends along the flow path, with its concentrations increasing downstream and low concentrations observed in the glacial meltwater and lakes (Table 1). \%DON showed an opposite trend to that of nitrate (Table 1). Other inorganic nitrogen species and phosphate $\left(\mathrm{PO}_{4}{ }^{3-}\right)$ concentrations were consistently low (Table 1). The DOC concentrations were $<75 \mu \mathrm{M}$ and showed fluctuating trends in both streams with the highest DOC concentration observed in Lake Yukidori (Table 1). SUVA $_{254}$ and $S_{275-295}$ varied almost mirror-symmetrically in both streams, with more pronounced changes observed in the Yukidori Valley. The lake samples particularly had low SUVA $_{254}$ and high $S_{275-295}$ values (Figure 1).

EEM-PARAFAC (Figures 1 and S2) revealed seven fluorescence components in our data set: two protein-like components $\left(\mathrm{C}_{325}\right.$ and $\left.\mathrm{C}_{300}\right)$, one microbial-derived component $\left(\mathrm{C}_{360}\right)$, one photorefractory humic-like component $\left(\mathrm{C}_{460}\right)$, and three photodegradable humic-like components $\left(\mathrm{C}_{415}, \mathrm{C}_{440}\right.$, and $\left.\mathrm{C}_{500}\right) .{ }^{19}$ The relative abundance of $\mathrm{C}_{360}$ and $\mathrm{C}_{460}$ remained almost constant and consistently low, while that of the protein-like components and photodegradable humiclike components varied largely (Figures 1 and S1). The protein-like components and photodegradable humic-like components showed very similar patterns as $S_{275-295}$ and SUVA $_{254}$, respectively, with high protein-like component contributions and low photodegradable humic-like component contributions in the lakes (Figure 1).

${ }^{1} \mathrm{H}$ NMR of bulk water revealed many well-resolved ${ }^{1} \mathrm{H}$ signals, indicating that a sizeable fraction of the stream DOM was composed of a mixture of small, identifiable molecules (Figures 2 and S3). For example, a large intensity singlet due to the $\mathrm{CH}_{3}$ group of acetic acid and a doublet due to the $\mathrm{CH}_{3}$ group of lactic acid were observed at 1.92 and $1.34 \mathrm{ppm}$, respectively (Figures 2 and S3). A quartet due to the $\mathrm{CH}$ 

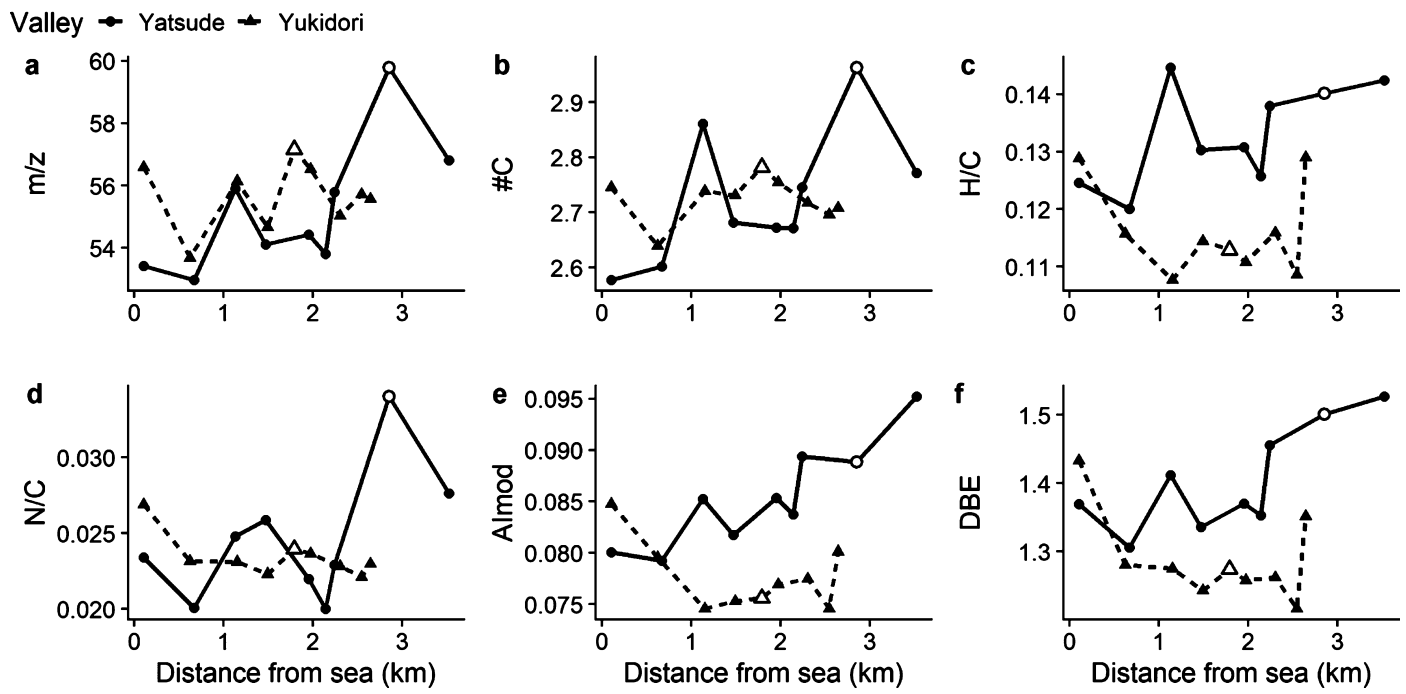

Figure 3. Downstream changes (right to left) of the functional molecular diversity of $m / z$ values (a), number of C atoms (b), H/C ratios, (d), N/C ratios, (e) modified aromaticity index $\left(\mathrm{AI}_{\text {mod }}\right)$, and (f) DBE in the Yukidori and Yatsude Valleys. Blank symbols represent lake water samples.

group of lactic acid was also observed at around $4.16 \mathrm{ppm}$ in the majority of samples (Figure 2). ${ }^{13}$ Formic acid at $8.5 \mathrm{ppm}$ was observed in all samples, while some samples had observable signals in aromatic (amide) regions between 7 and 8 ppm (Figures 2 and S3). Nevertheless, broad ${ }^{1} \mathrm{H}$ NMR profiles characteristic of complex DOM mixtures were observed in all samples superimposed by the resolved signals (Figure 2). Aromatic $\mathrm{H}$ contributions were low $(<5 \%$, Table S1) and likely derived from proteinaceous materials.

In each of the SPE-DOM samples, 3500-8000 molecular formulae were detected by FT-ICR MS (Table S2). Intensityweighted averages of the molar ratios $(\mathrm{H} / \mathrm{C}$ and $\mathrm{O} / \mathrm{C})$ and mass-to-charge ratio $(\mathrm{m} / \mathrm{z})$ of the molecular formulae varied little among samples (Table S2). The ranges of $\mathrm{H} / \mathrm{C}, \mathrm{O} / \mathrm{C}$, and $m / z$ were $1.31-1.39,0.40-0.44$, and $340.5-363.1$, respectively (Table S2). The intensity-weighted averages of the modified aromaticity index $\left(\mathrm{AI}_{\text {mod }}\right)^{37}$ ranged between 0.193 and 0.249 (Table S2). The relative contributions from molecular compound groups estimated by FT-ICR MS were similar in the two valleys, in the order of highly unsaturated (HU) O-poor compounds $>$ unsaturated compounds $>\mathrm{HU}$ Orich compounds $>$ unsaturated compounds with $\mathrm{N} \approx$ aromatic compounds $>$ saturated compounds $\approx$ condensed aromatic compounds (Figure 1). CHO-only molecular formulae consisted of $60-74 \%$ of the assigned molecular formulae, followed by $\mathrm{CHON}$-containing formulae (21-34\%) (Table S2).

The functional molecular diversity for each FT-ICR MS index exhibited diverging trends between streams (Figure 3). In the Yatsude Valley, the functional diversity for all indices was highest either in glacial meltwater or in Lake Heito and decreased downstream; while in the Yukidori Valley, the functional diversity for all indices remained almost constant or increased downstream. The functional diversity of glacial meltwater DOM was always higher in the Yatsude Valley, while the opposite was observed at the most downstream sampling point (outlet to the sea). L. Heito increased the functional diversity of DOM with respect to $m / z$, number of $\mathrm{C}$ atoms, and $\mathrm{N} / \mathrm{C}$ ratio (Figure 3 ).

CoDa-PCA holistically revealed molecular compositional differences between samples and detected differences in DOM composition between the valleys (Figure 4). PC1 explained $37.8 \%$ of the compositional variance in the data. PC1 correlated positively with the relative proportion (relative to the mean of all elements considered) of HU compounds, $\mathrm{CHO}$-only molecular formulae, and photorefractory humic-like fluorescence $\left(\% \mathrm{C}_{460}\right)$. PC1 correlated negatively with the relative proportion of saturated compounds and some heteroatom-containing molecular formulae (CHOP, CHONP, and CHONS) (Figure 4a). There was a clear split on PC1 between samples dominated by $\mathrm{HU}$ compounds (positive PC1) and by saturated compounds (negative PC1). Samples from the Yukidori and Yatsude Valleys were roughly separated on PC1 by these compounds (Figure 4b). PC2 explained further $25.4 \%$ of the compositional variance and correlated positively with the relative proportion (relative to the mean of all elements considered) of humic-like fluorescence (\%C415, \%C440, and \%C500) and aromatic and condensed aromatic compounds. PC2 correlated negatively with the relative proportion of protein-like fluorescence (\%C325), unsaturated compounds including those with $\mathrm{N}$ (e.g., peptides), and $\mathrm{CHON}$ molecular formulae (Figure 4a). PC2 split samples dominated by a "terrestrial" signature (positive PC2) and those with a microbial signature (negative PC2). Yukidori downstream samples were more enriched in aromatic compounds and humic-like fluorescence (Figure 4b), which was in accordance with the findings from Figure 1.

\section{DISCUSSION}

4.1. Source and Nature of DOM in the Streams. The set of employed analytical techniques consistently indicated the predominant microbial origin of DOM as expected. For instance, the dominance of $\mathrm{HU} \mathrm{O}$-poor compounds over $\mathrm{HU}$ O-rich compounds was a stark contrast to the dominance of the latter (such as phenolics) in DOM from forested catchments (Figure 1). ${ }^{48}$ Compared to DOM from ten of the largest world rivers, ${ }^{49} \mathrm{AI}_{\text {mod }}$ and $m / z$ values were lower and the proportions of $\mathrm{N}$-containing molecular formulae were much higher (Table S2). The low DOC/DON ratio and the UV-based indices (high $S_{275-295}$ and low SUVA $_{254}$ ) also supported the microbial origin of DOM in the streams. Typically, a higher (steeper) $S_{275-295}$ value suggests a decrease 
a

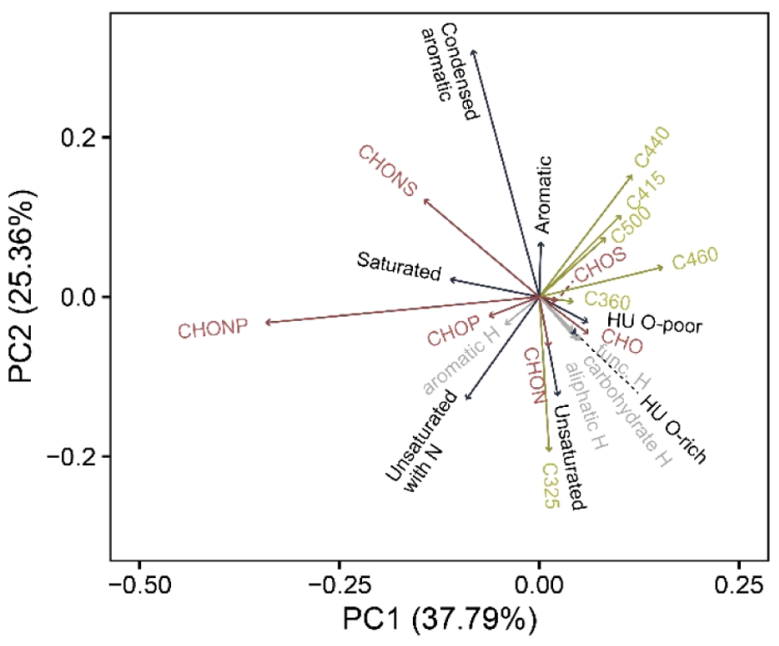

b

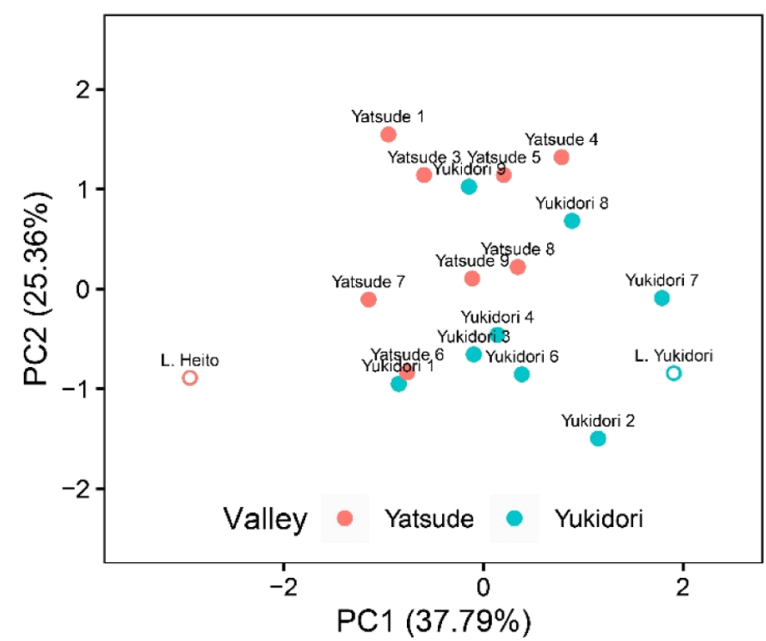

Figure 4. Compositional data-principal component analysis (CoDaPCA) of the Yukidori and Yatsude Valleys DOM composition, with centered logratio (clr)-transformation of $\mathrm{CoDa}$, where all the four compositions were taken as a single composition to compute the clr. Arrows are color-coded according to the compositions for visualization. (a) Interpretations of the relationships between arrows should follow the special rules of the CoDa-biplot. Briefly, the fundamental elements of a CoDa-biplot are the links between arrow heads, not the arrows themselves. See the manuscript for details. Distances among objects in (b) are approximations of their Aitchison distances in the multidimensional space. Samples are numbered from 1 to 9 along the flow path, and lake samples are represented by the blank circles. Abbreviations: $\mathrm{HU}$, highly unsaturated and func. $\mathrm{H}$, functionalized $\mathrm{H}$.

in aromaticity of DOM and an increase in the degree of photodegradation. ${ }^{20,23}$ The low $\mathrm{SUVA}_{254}$ values, an indicator of the aromaticity of $\mathrm{DOM}^{5}$ found in the studied streams (mostly $<1 \mathrm{~L} \mathrm{mg} \mathrm{C}^{-1} \mathrm{~m}^{-1}$ ) were comparable to or lower than that of offshore marine DOM. ${ }^{50}$ Nevertheless, the $\mathrm{SUVA}_{254}$ values were higher and the $S_{275-295}$ values were lower than observed in other Sôya Coast lakes and similar to that of lake porewater. ${ }^{19}$ This low $S_{275-295}$ value suggests that the stream water DOM was not as much photodegraded as in lakes in the same region because photobleaching is known to increase the $S_{275-295}$ values. $^{20,23}$ The relative abundance of the photodegradable humic-like components was higher $(27-58 \%$ in streams) than other Soya Coast lakes $(6-35 \%),{ }^{19}$ further supporting the findings of the UV-based indices that the stream water DOM was not as much photodegraded (Figure 1)

DOM in the streams consisted largely of a mixture of small, identifiable molecules according to the dominant and wellresolved ${ }^{1} \mathrm{H}$ signals (Figures 2 and $\mathrm{S} 3$ ). This corroborates previous findings that DOM contained in polar glaciers is largely a mixture of microbial-derived small molecules such as small organic acids, amino acids, and sugars derived from bacterial energy cycles and metabolism. ${ }^{13,14}$ However, the studied Antarctic stream DOM possessed distinct molecular and elemental properties compared to that of the ocean, which is also almost entirely microbial-derived. Marine DOM generally has much broader, mostly unresolved ${ }^{1} \mathrm{H}$ NMR signals because of the great diversity of functional groups and molecular environments as a result of extensive microbial processing. ${ }^{6,30,51}$ Accordingly, our results indicate that DOM in the Antarctic streams is of microbial origin and not yet highly processed through continuous microbial reworking like in the ocean. The low DOC/DON ratios (median 5.7, Table 1) were in the range of that of microbial biomass, supporting that the Antarctic stream DOM was at the very beginning of the microbial degradation network.

The similarity of the compound group contributions between the valleys and less in-stream variability than other spectroscopic techniques applied to bulk DOM may be due to the low extraction efficiencies by PPL (Table S2). The low recovery rate was probably because the majority of stream DOM was composed of hydrophilic monomers such as small organic acids and polar carbohydrates, which are too polar to be retained by PPL (Figures 2 and S3). In addition, colloidal organic matter, which by operational definition is part of DOM, does not penetrate the pore space of PPL and is presumably poorly retained. ${ }^{52}$ The solid-phase extraction procedure of DOM by PPL was optimized to recover a maximum $(\sim 65 \%)$ of highly processed DOM from marine and fresh waters. ${ }^{32}$ As such, the extraction efficiency of DOM by PPL increases during experiments with progressing microbial processing of phytoplankton-derived or monomeric DOM. ${ }^{53,54}$ Overall, the low extraction efficiency, low DOC/DON ratios, and well-resolved ${ }^{1} \mathrm{H}$ NMR signals all consistently pointed toward a recent microbial source and lack of strong microbial processing of DOM in the streams.

The four humic-like fluorescence components resolved by EEM-PARAFAC may be counterintuitive to the well-resolved ${ }^{1} \mathrm{H}$ signals indicating the dominance of small biomolecules (Figures 1 and 2). Humic-like fluorescence is usually attributed to aromatic terrestrial OM such as partial degradation products of lignin and phenols. ${ }^{55}$ One possibility is that concentrations of the fluorescent constituents responsible for the humic-like fluorescence (moss-derived phenols or terrestrial OM from atmospheric deposition ${ }^{56}$ ) were too low to be detected by NMR. ${ }^{14}$ However, increasing numbers of evidence point out that certain fluorescence components reoccur irrespective of the sample source..$^{24,57,58}$ The three photodegradable humiclike components in this study correspond to recently proposed three ubiquitous components. ${ }^{19,24}$ Exudation by phytoplankton and bacteria ${ }^{59,60}$ or physicochemical reactions such as crosslinking of lipid precursors in the presence of dissolved nitrogen ${ }^{61}$ can result in humic-like fluorescence, none of which is aromatic in nature. Therefore, another possibility is that the emergence of humic-like fluorescence may not necessarily require compounds that resonate in the aromatic 
chemical shift region in ${ }^{1} \mathrm{H}$ NMR. Considering the biogeochemical importance of the photoreactive fraction of $\mathrm{DOM}^{5,20,24,55}$ clarifying mechanisms leading to the emergence of the reoccurring fluorescence deserves future research.

4.2. Downstream Processing of DOM in the Streams. Clear downstream changes in the DOM composition were evident in the Yukidori Valley, especially in its bulk properties analyzed by spectroscopic techniques (Figure 1). For instance, parameters associated with a microbial signature $\left(S_{275-295}, \%\right.$ protein-like fluorescence, carbohydrate $\mathrm{H}$ ) increased, while those with an apparent "terrestrial" signature $\left(\mathrm{SUVA}_{254}, \%\right.$ ubiquitous humic-like fluorescence) decreased in Lake Yukidori (Figure 1). ${ }^{5,20,55}$ Similar patterns were also observed in Lake Heito (Figure 1). As fluorescence intensity of proteinlike and humic-like components increased and decreased, respectively (Table S1, Figure S2), both the photodegradation $^{20,23}$ and in situ microbial production of $\mathrm{DOM}^{4}$ within the lakes occurred simultaneously. In both streams, nitrate concentrations increased downstream, while showing low values in the meltwater and lakes (Table 1). These trends may indicate that nitrate was supplied to the streams from surrounding sea-bird nests as a result of nitrification of feces and consumed by phytoplankton and benthic phototrophs within the lakes. The simultaneous increase in DOC and DON concentrations (Table 1), protein-like fluorescence (Table S1), and carbohydrate $\mathrm{H}$ (Figure 1) all indicated an active microbial production of DOM within the lakes. Thus, lakes play an important role in the downstream fate of glacial DOM and nutrients by enhancing water residence time leading to larger DOM production and processing.

The progressive downstream increases in the relative contribution of aromatic and condensed aromatic compound groups (from 2.3 to $4.7 \%$ ) and $\mathrm{HU} \mathrm{O}$-poor compound groups (52-61\%) after Lake Yukidori indicated the supply of these compound groups from the stream bank vegetation such as mosses and/or their selective preservation in the Yukidori Valley (Figure 1). The intensity-weighted average of $\mathrm{AI}_{\text {mod }}$ and DBE also showed clear increase downstream, while $\mathrm{H} / \mathrm{C}$ (saturation) decreased (Figure S4). The optical parameters (increase in $\mathrm{SUVA}_{254}$ and \%ubiquitous humic-like fluorescence) $)^{5,55}$ and $\mathrm{H}$ distributions (increase in functionalized $\mathrm{H})^{30,62}$ supported the findings of FT-ICR MS (Figure 1). Mosses are enriched in phenolic compounds such as $p$ hydroxyacetophenone, $p$-hydroxybenzaldehyde, and $p$-hydroxybenzoic acid. ${ }^{63,64}$ Therefore, abundant mosses only found in the Yukidori Valley likely influenced its DOM composition by contributing aromatic and HU compounds (Figures 1 and S4). The increase in aromaticity of DOM could also be due to the microbial processing of freshly produced DOM. In the deep ocean, C-specific absorbance of DOM and presumably its aromaticity increases with time. ${ }^{65}$ This "browning" is not due to external terrestrial inputs but due to microbial reworking of DOM.

The ${ }^{1} \mathrm{H}$ NMR spectra highlighted the difference between Yukidori and Yatsude DOM constituents and their downstream processing that were not observable by bulk optical properties (Figure 2). ${ }^{1} \mathrm{H}$ NMR profiles of the starting point of the streams (Yukidori 1 and Yatsude 1) were similar, except for higher contribution from lactic acid in Yukidori 1 (Figures 2 and S3), indicating that differences in downstream ${ }^{1} \mathrm{H}$ NMR spectra between the valleys could be ascribed to in-stream processes. The most notable difference was the lack of sharp signals from small molecules and the overall downstream broadening of Yukidori ${ }^{1} \mathrm{H}$ NMR spectra (Figure 2). In contrast, Yatsude DOM remained much sharper signals derived from small molecules in carbohydrate and aliphatic $\mathrm{H}$ regions (Figure 2). Furthermore, distinct signals at the aromatic (amide) region were also evident in Yatsude DOM, which were absent in its meltwater (Yatsude 1) (Figure 2). This indicates that there was a production of amino acids and/ or peptides in the Yatsude Valley and that these presumably highly labile biomolecules were not fully degraded during the flow paths. Generally, ${ }^{1} \mathrm{H}$ spectral line broadening is associated with degradation of identifiable biomolecules and microbial reworking of primary producers' exudates. ${ }^{51}$ Paramagnetic species can also broaden NMR spectra, but they cannot explain the lack of sharp signals from small molecules (Figure 2). Thus, these results collectively suggest that microbial reworking of DOM may be more active in the Yukidori Valley than in the Yatsude Valley.

The functional molecular diversity of solid-phase extracted DOM chemical properties estimated by FT-ICR MS revealed another novel aspect of downstream processing of DOM (Figure 3). The decreasing functional diversity in the Yatsude Valley suggests the increasing homogeneity of DOM along the flow paths with respect to the chosen chemical properties; while in the Yukidori Valley, the constant or even increasing functional diversity was observed for all indices (Figure 3). These diverging trends in functional diversity could be explained by the presence/absence of river bed/bank mosses and associated material inputs. In the Yukidori Valley with abundant mosses, especially after Lake Yukidori, aromatic compounds were supplied from living and decomposing mosses to the stream. ${ }^{19}$ These material inputs particularly increased the functional diversity regarding aromaticity $\left(\mathrm{AI}_{\mathrm{mod}}\right.$, $\mathrm{DBE}$ ) and saturation $(\mathrm{H} / \mathrm{C}$ ) (Figure 3c,e,f). In the Yatsude Valley with few mosses, new material inputs from vegetation were limited. Thus, the reduction in the functional diversity with respect to molecular weight $(\mathrm{m} / \mathrm{z}, \mathrm{\# C}$ ) (Figure $3 \mathrm{a}, \mathrm{b}$ ) could be explained by preferential remineralization of high molecular mass compounds by microorganisms along the flow path. ${ }^{66}$ Degraded DOM with fewer larger molecules shows lower functional diversity, while fresh DOM, containing both large and small molecules, shows a high functional diversity with respect to molecular weight $\left(\mathrm{m} / z\right.$, \#C). ${ }^{36}$ Note that, here, we refer to "large" and "small" molecules in terms of the analytical window of FT-ICR MS $(>92 \mathrm{~m} / z)$, while "small" molecules contributing to the observed sharp signals in the ${ }^{1} \mathrm{H}$ NMR spectra (Figure 2) had a lower molecular weight $(\leq 90)$ and were outside of the analytical window of FT-ICR MS. The intensity-weighted average of $\mathrm{m} / z$ values of Yatsude samples generally decreased downstream and had strong linear correlations with the functional diversity of all considered chemical properties (Figures S4 and S5). This indicated that downstream preferential remineralization of high molecular mass compounds was a major factor that decreased the functional diversity of solid-phase extracted DOM (Figure 3). A list of the top 20 largest-mass molecular formulae that decreased downstream in relative intensity in the Yatsude Valley is presented in Table S5. These were mostly CHO-only molecular formulae (Table S5). Meanwhile, the increased functional diversity regarding molecular weight $(\mathrm{m} / z, \# \mathrm{C})$ and relative $\mathrm{N}$ abundance $(\mathrm{N} / \mathrm{C}$ ) in the Lake Heito suggests a new in situ production of proteinaceous DOM, which was strongly supported by the distinct amide ${ }^{1} \mathrm{H}$ NMR signals and elevated protein-like fluorescence in Lake Heito DOM (Figure $2 \mathrm{~b}$ and 
Table S1). Lists of the $\mathrm{N}$-containing molecular formulae that increased more than $200 \%(n=49)$ in relative intensity or were newly generated $(n=953)$ at L. Heito are presented in Tables S6 and S7. Such a new production did not increase the functional diversity regarding aromaticity $\left(\mathrm{AI}_{\bmod }, \mathrm{DBE}\right)$ because of a lack of newly synthesized aromatic compounds by microbes (Figure 3e,f).

4.3. Fate of DOM in the Streams. Condensed aromatic compounds and CHONS and CHONP molecular formulae proportionally varied greatly considering the longest arrows in the CoDa-PCA biplot (Figure 4a). Consequently, these variables were those having high relative variations, reflected by long distances between the vertices of clr-variables (Figure 4a). This is in accordance with their high logratio variances (Table S3). Care should be taken here because a small fraction tends to have a large relative analytical error and may distort the CoDa-biplot. We confirmed that this is not the case in this study because variation between samples was sufficiently high for all parameters compared to analytical errors (Table S4). The proportionally high variations of these molecular compounds suggest that they underwent rapid production and consumption in the streams, for instance, by microbial production, bacterial consumption, and photodegradation. ${ }^{19,24,49,62}$ Additionally, the short link between the vertices of the arrows of $\mathrm{HU} \mathrm{O}$-rich/O-poor compounds indicates that their ratio is nearly constant throughout the data set (Figure 4a), which implies that these molecular compound groups were tightly associated and moved in parallel in the studied streams and that their relative abundance (percentages) was mostly determined by change in other compound groups' abundance. This is a new finding that was not observed by a raw PCA with original non-clr-transformed data where these compound groups seemed to be negatively correlated as a result of a presumably spurious correlation (not reported). Similar associated behaviors can be observed among photodegradable humic-like components $\left(\mathrm{C}_{415}, \mathrm{C}_{440}\right.$, and $\left.\mathrm{C}_{500}\right)$ and among aliphatic $\mathrm{H}$, functionalized $\mathrm{H}$, and carbohydrate $\mathrm{H}$ (Figure 4a).

In summary, this study shows that glacial DOM is largely a mixture of microbial-derived small molecules, consistent with the past findings. ${ }^{13,14}$ Glacial DOM is actively processed along the flow path before entering the ocean. The extent how much glacial DOM undergoes processing and receives new production depends on the environmental conditions such as vegetation. Lakes also play an important role in the downstream fate of glacial DOM and nutrients by enhancing water residence time leading to larger DOM production and processing. Whether glacial runoff is associated with inputs of biologically labile substrates to the ocean ${ }^{15}$ depends on downstream environments and associated processing of glacial DOM

\section{ASSOCIATED CONTENT}

\section{SI Supporting Information}

The Supporting Information is available free of charge at https://pubs.acs.org/doi/10.1021/acs.est.1c03163.

Detailed descriptions of sampling and FT-ICR MS data processing; map of the study site; EEM spectra; nonmagnified ${ }^{1} \mathrm{H}$ NMR spectra presented in Figure 2; downstream change in intensity-weighted average of FTICR MS-derived DOM molecular indices; correlations between the intensity-weighted average of $\mathrm{m} / z$ values and the functional diversity; UV-based index, EEMPARAFAC, and NMR data; FT-ICR MS data; variation array; comparison of intersample variance and analytical precision of FT-ICR MS parameters; list of the top 20 largest-mass molecular formulae that decreased downstream in the Yatsude Valley; list of the N-containing molecular formulae that increased more than $200 \%$ at $\mathrm{L}$. Heito; and list of the $\mathrm{N}$-containing molecular formulae that were generated at L. Heito (PDF)

\section{AUTHOR INFORMATION}

\section{Corresponding Authors}

Morimaru Kida - Research Group for Marine Geochemistry (ICBM-MPI Bridging Group), Institute for Chemistry and Biology of the Marine Environment (ICBM), University of Oldenburg, Oldenburg 26129, Germany; Present

Address: Soil Science Laboratory, Graduate School of Agricultural Science, Kobe University, 1-1 Rokkodai, Nada, Kobe, Hyogo 657-8501, Japan (M.K.);

○ orcid.org/0000-0002-9908-2012;

Email: morimaru.kida@uni-oldenburg.de

Nobuhide Fujitake - Soil Science Laboratory, Graduate School of Agricultural Science, Kobe University, Kobe, Hyogo 657-8501, Japan; Email: fujitake@kobe-u.ac.jp

Thorsten Dittmar - Research Group for Marine Geochemistry (ICBM-MPI Bridging Group), Institute for Chemistry and Biology of the Marine Environment (ICBM), University of Oldenburg, Oldenburg 26129, Germany; Helmholtz Institute for Functional Marine Biodiversity (HIFMB) at the University of Oldenburg, Oldenburg 26129, Germany; Email: thorsten.dittmar@uni-oldenburg.de

\section{Authors}

Taichi Kojima - Soil Science Laboratory, Graduate School of Agricultural Science, Kobe University, Kobe, Hyogo 6578501, Japan

Yukiko Tanabe - National Institute of Polar Research, Research Organization of Information and Systems, Tokyo 190-8518, Japan; Department of Polar Science, SOKENDAI (The Graduate University for Advanced Studies), Tokyo 190-8518, Japan

Kentaro Hayashi - Institute for Agro-Environmental Sciences, NARO, Tsukuba, Ibaraki 305-8604, Japan

Sakae Kudoh - National Institute of Polar Research, Research Organization of Information and Systems, Tokyo 190-8518, Japan; Department of Polar Science, SOKENDAI (The Graduate University for Advanced Studies), Tokyo 1908518, Japan

Complete contact information is available at: https://pubs.acs.org/10.1021/acs.est.1c03163

\section{Notes}

The authors declare no competing financial interest.

\section{ACKNOWLEDGMENTS}

We are indebted to all those who provided essential logistical support in the field during the 58th Japanese Antarctic Research Expedition. Discussion with Juan José Egozcue (Universitat Politècnica de Catalunya) and Vera PawlowskyGlahn (Universitat de Girona) greatly helped our understanding of compositional data analysis. We are also thankful to Matthias Friebe, Katrin Klaproth, and Ina Ulber (University of 
Oldenburg) for technical assistance. This study was financially supported by JSPS KAKENHI $16 \mathrm{H} 05885$ and grant-in-aid for JSPS Overseas Research Fellow (201960090). The authors declare no competing financial interest. DOM molecular composition data by FT-ICR MS are available at PANGAEA (https://doi.org/10.1594/PANGAEA.931814).

\section{REFERENCES}

(1) Findlay, S. E. G.; Sinsabaugh, R. L. Aquatic Ecosystems; Elsevier, 2003.

(2) Thurman, E. M. Organic Geochemistry of Natural Waters; Thurman, E. M., Ed.; Springer Netherlands: Dordrecht, 1985.

(3) Hedges, J. I.; Keil, R. G.; Benner, R. What happens to terrestrial organic matter in the ocean? Org. Geochem. 1997, 27, 195-212.

(4) Kellerman, A. M.; Kothawala, D. N.; Dittmar, T.; Tranvik, L. J. Persistence of dissolved organic matter in lakes related to its molecular characteristics. Nat. Geosci. 2015, 8, 454-457.

(5) Weishaar, J. L.; Aiken, G. R.; Bergamaschi, B. A.; Fram, M. S.; Fujii, R.; Mopper, K. Evaluation of specific ultraviolet absorbance as an indicator of the chemical composition and reactivity of dissolved organic carbon. Environ. Sci. Technol. 2003, 37, 4702-4708.

(6) Hertkorn, N.; Harir, M.; Koch, B. P.; Michalke, B.; SchmittKopplin, P. High-field NMR spectroscopy and FTICR mass spectrometry: Powerful discovery tools for the molecular level characterization of marine dissolved organic matter. Biogeosciences 2013, 10, 1583-1624.

(7) Schmitt-Kopplin, P.; Hemmler, D.; Moritz, F.; Gougeon, R. D.; Lucio, M.; Meringer, M.; Müller, C.; Harir, M.; Hertkorn, N. Systems chemical analytics: introduction to the challenges of chemical complexity analysis. Faraday Discuss. 2019, 218, 9-28.

(8) Roth, V.-N.; Lange, M.; Simon, C.; Hertkorn, N.; Bucher, S.; Goodall, T.; Griffiths, R. I.; Mellado-Vázquez, P. G.; Mommer, L.; Oram, N. J.; Weigelt, A.; Dittmar, T.; Gleixner, G. Persistence of dissolved organic matter explained by molecular changes during its passage through soil. Nat. Geosci. 2019, 12, 755-761.

(9) Drake, T. W.; Wickland, K. P.; Spencer, R. G. M.; McKnight, D. M.; Striegl, R. G. Ancient low-molecular-weight organic acids in permafrost fuel rapid carbon dioxide production upon thaw. Proc. Natl. Acad. Sci. 2015, 112, 13946-13951.

(10) Roebuck, J. A.; Seidel, M.; Dittmar, T.; Jaffé, R. Land Use Controls on the Spatial Variability of Dissolved Black Carbon in a Subtropical Watershed. Environ. Sci. Technol. 2018, 52, 8104-8114.

(11) Jacob, T.; Wahr, J.; Pfeffer, W. T.; Swenson, S. Recent contributions of glaciers and ice caps to sea level rise. Nature 2012, 482, 514-518.

(12) Chen, J. L.; Wilson, C. R.; Blankenship, D.; Tapley, B. D. Accelerated Antarctic ice loss from satellite gravity measurements. Nat. Geosci. 2009, 2, 859-862.

(13) Pautler, B. G.; Simpson, A. J.; Simpson, M. J.; Tseng, L.-H.; Spraul, M.; Dubnick, A.; Sharp, M. J.; Fitzsimons, S. J. Detection and structural identification of dissolved organic matter in Antarctic glacial ice at natural abundance by SPR-W5-WATERGATE $1 \mathrm{H}$ NMR spectroscopy. Environ. Sci. Technol. 2011, 45, 4710-4717.

(14) Pautler, B. G.; Woods, G. C.; Dubnick, A.; Simpson, A. J.; Sharp, M. J.; Fitzsimons, S. J.; Simpson, M. J. Molecular characterization of dissolved organic matter in glacial ice: Coupling natural abundance $1 \mathrm{H}$ NMR and fluorescence spectroscopy. Environ. Sci. Technol. 2012, 46, 3753-3761.

(15) Hood, E.; Fellman, J.; Spencer, R. G. M.; Hernes, P. J.; Edwards, R.; D'Amore, D.; Scott, D.; D'Amore, D.; Scott, D. Glaciers as a source of ancient and labile organic matter to the marine environment. Nature 2009, 462, 1044-1047.

(16) Kudoh, S.; Tanabe, Y. Limnology and ecology of lakes along the Sôya Coast, East Antarctica. Adv. Polar Sci. 2014, 25, 75-91.

(17) Kanda, H.; Imura, S.; Ueno, T. On the structures of moss colony in the Yukidori Valley, Langhovde, East Antarctica. Polar Biosci. 2004, 17, 128-138.
(18) Kudoh, S.; Tanabe, Y.; Inoue, T.; Imura, S.; Kanda, H. Breaching of a perennial snow dam below lake hyoga ike in the langhovde region of the soya coast, East Antarctica: Probable effect of disturbance events on the distribution and colonization of flora within/around the lake. Antarct. Rec. 2009, 53, 114-122.

(19) Kida, M.; Kojima, T.; Tanabe, Y.; Hayashi, K.; Kudoh, S.; Maie, N.; Fujitake, N. Origin, distributions, and environmental significance of ubiquitous humic-like fluorophores in Antarctic lakes and streams. Water Res. 2019, 163, 114901.

(20) Helms, J. R.; Stubbins, A.; Ritchie, J. D.; Minor, E. C.; Kieber, D. J.; Mopper, K. Absorption spectral slopes and slope ratios as indicators of molecular weight, source, and photobleaching of chromophoric dissolved organic matter. Limnol. Oceanogr. 2008, 53, 955-969.

(21) Hu, C.; Muller-Karger, F. E.; Zepp, R. G. Absorbance, absorption coefficient, and apparent quantum yield: A comment on common ambiguity in the use of these optical concepts. Limnol. Oceanogr. 2002, 47, 1261-1267.

(22) Murphy, K. R.; Stedmon, C. a.; Graeber, D.; Bro, R. Fluorescence spectroscopy and multi-way techniques. PARAFAC. Anal. Methods 2013, 5, 6557.

(23) Fichot, C. G.; Benner, R. The spectral slope coefficient of chromophoric dissolved organic matter (S275-295) as a tracer of terrigenous dissolved organic carbon in river-influenced ocean margins. Limnol. Oceanogr. 2012, 57, 1453-1466.

(24) Murphy, K. R.; Timko, S. A.; Gonsior, M.; Powers, L. C.; Wünsch, U. J.; Stedmon, C. A. Photochemistry illuminates ubiquitous organic matter fluorescence spectra. Environ. Sci. Technol. 2018, 52, $11243-11250$.

(25) Kida, M.; Tanabe, M.; Tomotsune, M.; Yoshitake, S.; Kinjo, K.; Ohtsuka, T.; Fujitake, N. Changes in dissolved organic matter composition and dynamics in a subtropical mangrove river driven by rainfall. Estuar. Coast Shelf Sci. 2019, 223, 6-17.

(26) Tanabe, Y.; Yasui, S.; Osono, T.; Uchida, M.; Kudoh, S.; Yamamuro, M. Abundant deposits of nutrients inside lakebeds of Antarctic oligotrophic lakes. Polar Biol. 2017, 40, 603-613.

(27) Lam, B.; Simpson, A. J. Direct 1H NMR spectroscopy of dissolved organic matter in natural waters. Analyst 2008, 133, 263269.

(28) Kida, M.; Sato, H.; Okumura, A.; Igarashi, H.; Fujitake, N. Introduction of DEAE Sepharose for isolation of dissolved organic matter. Limnology 2019, 20, 153.

(29) Woods, G. C.; Simpson, M. J.; Koerner, P. J.; Napoli, A.; Simpson, A. J.; Simpson, J. HILIC-NMR: toward the identification of individual molecular components in dissolved organic matter. Environ. Sci. Technol. 2011, 45, 3880-3886.

(30) Hertkorn, N.; Benner, R.; Frommberger, M.; Schmitt-Kopplin, P.; Witt, M.; Kaiser, K.; Kettrup, A.; Hedges, J. I. Characterization of a major refractory component of marine dissolved organic matter. Geochim. Cosmochim. Acta 2006, 70, 2990-3010.

(31) Sleighter, R. L.; Caricasole, P.; Richards, K. M.; Hanson, T.; Hatcher, P. G. Characterization of terrestrial dissolved organic matter fractionated by $\mathrm{pH}$ and polarity and their biological effects on plant growth. Chem. Biol. Technol. Agric. 2015, 2, 9.

(32) Dittmar, T.; Koch, B.; Hertkorn, N.; Kattner, G. A simple and efficient method for the solid-phase extraction of dissolved organic matter (SPE-DOM) from seawater. Limnol Oceanogr. Methods 2008, 6, 230-235.

(33) Li, Y.; Harir, M.; Uhl, J.; Kanawati, B.; Lucio, M.; Smirnov, K. S.; Koch, B. P.; Schmitt-Kopplin, P.; Hertkorn, N. How representative are dissolved organic matter (DOM) extracts? A comprehensive study of sorbent selectivity for DOM isolation. Water Res. 2017, 116, 316323.

(34) Perminova, I. V.; Dubinenkov, I. V.; Kononikhin, A. S.; Konstantinov, A. I.; Zherebker, A. Y.; Andzhushev, M. A.; Lebedev, V. A.; Bulygina, E.; Holmes, R. M.; Kostyukevich, Y. I.; Popov, I. A.; Nikolaev, E. N. Molecular mapping of sorbent selectivities with respect to isolation of arctic dissolved organic matter as measured by 
fourier transform mass spectrometry. Environ. Sci. Technol. 2014, 48, $7461-7468$.

(35) Merder, J.; Freund, J. A.; Feudel, U.; Hansen, C. T.; Hawkes, J. A.; Jacob, B.; Klaproth, K.; Niggemann, J.; Noriega-Ortega, B. E.; Osterholz, H.; Rossel, P. E.; Seidel, M.; Singer, G.; Stubbins, A.; Waska, H.; Dittmar, T. ICBM-OCEAN: Processing ultrahighresolution mass spectrometry data of complex molecular mixtures. Anal. Chem. 2020, 92, 6832-6838.

(36) Mentges, A.; Feenders, C.; Seibt, M.; Blasius, B.; Dittmar, T. Functional molecular diversity of marine dissolved organic matter is reduced during degradation. Front. Mar. Sci. 2017, 4, 194.

(37) Koch, B. P.; Dittmar, T. From mass to structure: an aromaticity index for high-resolution mass data of natural organic matter. Rapid Commun. Mass Spectrom. 2016, 30, 250.

(38) Egozcue, J. J.; Pawlowsky-Glahn, V. Compositional Data: The Sample Space and its Structure; Springer Berlin Heidelberg, 2019; Vol. 28.

(39) Filzmoser, P.; Hron, K.; Reimann, C. Principal component analysis for compositional data with outliers. Environmetrics 2009, 20, 621-632.

(40) Aitchison, J. Principal component analysis of compositional data. Biometrika 1983, 70, 57-65.

(41) Pearson, K. Mathematical contributions to the theory of evolution.- On a form of spurious correlation which may arise when indices are used in the measurement of organs. Proc. R. Soc. London 1897, 60, 489-498.

(42) Aitchison, J.; Egozcue, J. J. Compositional data analysis: where are we and where should we be heading? Math. Geol. 2005, 37, 829850.

(43) Filzmoser, P.; Hron, K.; Reimann, C. Univariate statistical analysis of environmental (compositional) data: Problems and possibilities. Sci. Total Environ. 2009, 407, 6100-6108.

(44) Templ, M.; Hron, K.; Filzmoser, P. robCompositions: An Rpackage for robust statistical analysis of compositional data. Compositional Data Analysis; John Wiley \& Sons, Ltd: Chichester, U.K., 2011; pp 341-355.

(45) R Core Team. R A Language and Environment for Statistical Computing; R Foundation for Statistical Computing: Vienna, Austria, 2019.computer-program

(46) Aitchison, J.; Greenacre, M. Biplots of compositional data. J. R. Stat. Soc.-Ser. D Statistician 2002, 51, 375-392.

(47) Aitchison, J. Relative variation diagrams for describing patterns of compositional variability. Math. Geol. 1990, 22, 487-511.

(48) Spencer, R. G. M.; Kellerman, A. M.; Podgorski, D. C.; Macedo, M. N.; Jankowski, K.; Nunes, D.; Neill, C. Identifying the molecular signatures of agricultural expansion in Amazonian headwater streams. J. Geophys. Res.: Biogeosci. 2019, 124, 1637-1650.

(49) Riedel, T.; Zark, M.; Vähätalo, A. V.; Niggemann, J.; Spencer, R. G. M.; Hernes, P. J.; Dittmar, T. Molecular signatures of biogeochemical transformations in dissolved organic matter from ten world rivers. Front. Earth Sci. 2016, 4, 85.

(50) Massicotte, P.; Asmala, E.; Stedmon, C.; Markager, S. Global distribution of dissolved organic matter along the aquatic continuum: Across rivers, lakes and oceans. Sci. Total Environ. 2017, 609, 180191.

(51) Lechtenfeld, O. J.; Hertkorn, N.; Shen, Y.; Witt, M.; Benner, R. Marine sequestration of carbon in bacterial metabolites. Nat. Commun. 2015, 6, 6711.

(52) Hawkes, J. A.; Hansen, C. T.; Goldhammer, T.; Bach, W.; Dittmar, T. Molecular alteration of marine dissolved organic matter under experimental hydrothermal conditions. Geochim. Cosmochim. Acta 2016, 175, 68-85.

(53) Osterholz, H.; Niggemann, J.; Giebel, H.-A.; Simon, M.; Dittmar, T. Inefficient microbial production of refractory dissolved organic matter in the ocean. Nat. Commun. 2015, 6, 7422.

(54) Noriega-Ortega, B. E.; Wienhausen, G.; Mentges, A.; Dittmar, T.; Simon, M.; Niggemann, J. Does the chemodiversity of bacterial exometabolomes sustain the chemodiversity of marine dissolved organic matter? Front. Microbiol. 2019, 10, 215.
(55) Coble, P. G. Marine optical biogeochemistry: the chemistry of ocean color. Chem. Rev. 2007, 107, 402-418.

(56) Farzadnia, S.; Nimmagadda, R. D.; McRae, C. A comparative structural study of nitrogen-rich fulvic acids from various Antarctic lakes. Environ. Chem. 2017, 14, 502.

(57) Wünsch, U. J.; Bro, R.; Stedmon, C.; Wenig, P.; Murphy, K. Emerging patterns in the global distribution of dissolved organic matter fluorescence. Anal. Methods 2019, 11, 888.

(58) Ishii, S. K. L.; Boyer, T. H. Behavior of reoccurring PARAFAC components in fluorescent dissolved organic matter in natural and engineered systems: a critical review. Environ. Sci. Technol. 2012, 46, 2006-2017.

(59) Shimotori, K.; Watanabe, K.; Hama, T. Fluorescence characteristics of humic-like fluorescent dissolved organic matter produced by various taxa of marine bacteria. Aquat. Microb. Ecol. 2012, 65, 249-260.

(60) Fukuzaki, K.; Imai, I.; Fukushima, K.; Ishii, K.-I.; Sawayama, S.; Yoshioka, T. Fluorescent characteristics of dissolved organic matter produced by bloom-forming coastal phytoplankton. J. Plankton Res. 2014, 36, 685-694.

(61) Kieber, R. J.; Hydro, L. H.; Seaton, P. J. Photooxidation of triglycerides and fatty acids in seawater: Implication toward the formation of marine humic substances. Limnol. Oceanogr. 1997, 42, $1454-1462$

(62) Stubbins, A.; Dittmar, T. Illuminating the deep: Molecular signatures of photochemical alteration of dissolved organic matter from North Atlantic Deep Water. Mar. Chem. 2015, 177, 318-324.

(63) Williams, C. J.; Yavitt, J. B.; Wieder, R. K.; Cleavitt, N. L. Cupric oxide oxidation products of northern peat and peat-forming plants. Can. J. Bot. 1998, 76, 51-62.

(64) Spencer, R. G. M.; Aiken, G. R.; Wickland, K. P.; Striegl, R. G.; Hernes, P. J. Seasonal and spatial variability in dissolved organic matter quantity and composition from the Yukon River basin, Alaska. Global Biogeochem. Cycles 2008, 22, GB4002.

(65) Nelson, N. B.; Siegel, D. A.; Carlson, C. A.; Swan, C. M. Tracing global biogeochemical cycles and meridional overturning circulation using chromophoric dissolved organic matter. Geophys. Res. Lett. 2010, 37, L03610.

(66) Walker, B. D.; Beaupré, S. R.; Guilderson, T. P.; McCarthy, M. D.; Druffel, E. R. M. Pacific carbon cycling constrained by organic matter size, age and composition relationships. Nat. Geosci. 2016, 9, 888-891. 